\title{
Dimensões Socioeducativas do Teatro do Oprimido: Cultura, Teatro e Educação Populares
}

\author{
Thiago de Oliveira Alochio \\ Universidade Federal do Rio de Janeiro (UFRJ), Rio de Janeiro, Brasil
}

\begin{abstract}
Resumo: O presente artigo divide-se em duas partes: uma discussão com base em aportes teóricos e um relato de experiência. Num primeiro momento, partindo de uma breve narrativa histórica sobre o conceito de cultura popular enquanto uma categoria intelectual, presente em alguns movimentos sociais de esquerda brasileiros durante as décadas de 50 e 60, destaca a concepção deste conceito em Augusto Boal e caracteriza o Teatro do Oprimido dentro de uma determinada tradição de cultura popular, o teatro político, engajado. Por fim, relata uma experiência num curso de formação no Centro de Teatro do Oprimido que tem suscitado reflexões sobre a educação popular e o fazer pedagógico em geral.

Palavras-chave: Cultura popular. Teatro do Oprimido. Opressão. Pluralismo.
\end{abstract}

INTRODUÇÃO'

Em 3 de dezembro de 2015, na Câmara Municipal do Rio de Janeiro, foi realizada uma audiência pública cujo tema foi“Escola contra quem e a favor de quem?". Debateu-se o projeto de lei (PL 867/2014) que pretende instaurar - Programa Escola Sem Partido na rede pública de ensino do município. Seu objetivo é "vedar a prática da doutrinação política e ideológica em sala de aula, bem como a veiculação, em disciplina obrigatória, de conteúdos que possam estar em conflito com as convicções morais dos estudantes ou de seus pais" (BOLSONARO, 2014, Art. 2). Os artigos presentes em seu site², em sua totalidade, apesar de uma presunção de defesa do "pluralismo de ideias" no referido $\mathrm{PL}$, se propõem a caracterizar o sistema de ensino público brasileiro 
como doutrinário e totalitário. Como podemos ler num deles, intitulado Pedagogia do Opressor, "os educadores Freireanos são levados a 'libertar' crianças de uma opressão imaginária" e assim as ideias de Freire seriam "perigosas não somente para os alunos, mas também para os professores comprometidos com esse tipo de educação" (STERN, 2009, s.p.).

Neste artigo, considera-se esta discussão apenas como pano de fundo. O posicionamento é oposto a estes discursos na medida em que se percebe, não só um potencial educativo libertador e autonomista real na pedagogia de Paulo Freire e no Teatro do Oprimido de Augusto Boal, mas também que seus projetos estão de acordo com um efetivo "pluralismo de ideias" na arte e na educação. Propõe-se uma reflexão sobre educação e Teatro do Oprimido, enquanto fenômeno vivencial, num contexto que vai além da educação institucionalizada, em direção à cultura popular e suas práticas sociais concretas, que nos permita refletir sobre as possibilidades advindas desse processo. Neste sentido, os objetivos do artigo são os seguintes: (1) Abordar uma discussão teórica sobre a transformação do conceito de cultura popular nas décadas de 1950 e 1960. (2) Analisar a concepção de cultura popular em Augusto Boal e caracterizar o Teatro do Oprimido dentro de uma determinada tradição de cultura popular, o teatro popular engajado. (3) Relatar uma experiência num curso de formação no Centro de Teatro do Oprimido que possibilita (através de percepções acerca da teoria do Teatro do Oprimido (TO), dos sentidos da categoria "opressão" e da função do coringa nas relações entre os participantes de uma oficina de Teatro Fórum) reflexões sobre a educação popular no contexto atual e o fazer pedagógico em geral.

A fim de compreender o Teatro do Oprimido enquanto uma prática componente da cultura popular brasileira, questiona-se o próprio conceito de "cultura popular". Trata-se de um conceito ambivalente e complexo. Portanto, é preciso deixar claro, desde já, que não há objetivo de estabelecer neste ensaio uma definição que esgote todos os seus conteúdos e possibilidades. O que faz, então, partindo de sua a gênese, é destacar dois sentidos presentes em movimentos sociais e intelectuais brasileiros nas décadas de 50 e $60 .^{3}$ Assim forma-se uma base para indagar sobre o sentido de cultura popular em Boal.

\section{CULTURA POPULAR E POLÍTICAS CULTURAIS NAS DÉCADAS DE 50 E 60}

Diante do processo civilizatório iluminista e do seu ideal de Progresso, os costumes e valores tradicionais do povo estavam em descrédito. $O$ conceito 
de cultura popular surgiu na Alemanha, na virada do século XVIII para o XIX, quando intelectuais românticos, como Herder e os irmãos Grimm, estudaram a poesia popular tradicional e a caracterizaram como um tipo de cultura, ainda que contraposta à cultura erudita, de elite. Com o tempo, este campo de estudo se ampliou abarcando a música, práticas religiosas e outras "antiguidades populares", como chamavam na época. Já o termo folclore surge em meados do século XIX na Inglaterra, quando os vocábulos folk (povo) e lore (saber) foram articulados com o intuito de se referir aos saberes tradicionais de um povo, fundamento de sua nacionalidade (ORTIZ, 1989). No Brasil, os estudos sobre folclore começaram no final do século XIX, com o trabalho de precursores como Silvio Romero, e ganhou destaque, a partir dos anos 20, com os intelectuais modernistas. Entre as décadas de 40 e 60 , o tema ganhou notoriedade por meio da atuação da Sociedade de Etnografia e Folclore, da Comissão Nacional de Folclore e da Campanha em Defesa do Folclore Brasileiro (GUIMARÃES, 2012).

Contudo, desde os anos 50, pode-se notar o começo da desarticulação entre cultura popular e folclore e a relativa marginalização deste. Multiplicaram-se os estudos sobre a herança colonial e o imperialismo, estes estimulados por institutos de pesquisa e movimentos sociais de esquerda e/ ou contraculturais. No seio desses movimentos, o conceito de cultura popular, sem perder completamente sua acepção anterior, começa a relacionar-se à falta de "consciência política" do povo. Mas do povo enquanto "sociedade de massa", consumidores da "indústria cultural", uma concepção oriunda da Escola de Frankfurt. O sentido de cultura popular, antes relacionado à tradição e aos fundamentos do nacionalismo, bifurca-se na medida em que passa a se relacionar também com a ideia de revolução, na qual a cultura pôde ser concebida, segundo Catenacci, no âmbito de um projeto em "transformação" (CATENACCI, 2001, p. 32). Dois exemplos de movimentos sociais onde esta concepção de cultura popular era encontrada são o Centro Popular de Cultura (CPC) do Rio de Janeiro e o Movimento de Cultura Popular (MCP) do Recife.

Segundo Berlink (1984, p. 4), o CPC surgiu em 1961, com o objetivo de utilizar a arte para responder às questões políticas e sociais daquele momento, e durou até 64 quando foi extinto pelo regime militar. Constituído por um grupo de intelectuais de esquerda e artistas de diversas áreas, como teatro, música, cinema, literatura e artes plásticas, defendia um ideal de arte engajada e muitos de seus integrantes eram simpáticos ao Partido Comunista Brasileiro. Originou-se a partir de uma dissidência no Teatro de Arena de São Paulo, que tinha como propósito a crítica ao tipo de teatro predominante na época (baseado em repertórios estrangeiros, desconectado da realidade 
política brasileira e voltado para a classe média alta) propondo a formação de uma "consciência crítica" dos espectadores por meio da abordagem de temas políticos como em Revolução na América do Sul, de Augusto Boal, e A mais-valia vai acabar, seu Edgar, de Oduvaldo Vianna Filho. Contudo, insatisfeito com a incapacidade do Arena em atingir e conscientizar os setores populares mais distantes do poder, Vianna Filho, juntamente com outros integrantes, decidem fundar o CPC no Rio de Janeiro, com apoio da UNE.

No clima pós-guerra, em meio a um intenso debate sobre a ideologia desenvolvimentista nacional frente ao subdesenvolvimento, Roland Corbisier, membro do Instituto Superior de Estudos Brasileiros (ISEB), contribui para a difusão da noção de cultura como sinônimo de cultura nacional e da ideia segundo a qual, deveria se buscar na história do Brasil, o elemento cultural simbólico autêntico para construir um caminho próprio de desenvolvimento. Ele destacava a necessidade de superar o atraso econômico e cultural do país, que estava diretamente relacionado à herança colonial e ao imperialismo capitalista. Sua obra Formação e problema da cultura brasileira, de 1958, veio a influenciar o sociólogo Carlos Estevam Martins, membro do ISEB e do CPC (MANOEL; VALE, 2006, p. 4-5). Apesar de, como afirma Garcia (2004, p. 128129), o CPC não constituir um movimento homogêneo em torno de ideia da cultura popular, pode-se dizer que pelo menos para Martins, e para o grupo ligado a ele, a arte popular tradicional, como o folclore longe de ser um fundamento importante da nacionalidade, aparece como ingênua e de mera distração, ou seja, sem crítica. Já a "arte popular revolucionária" dizia respeito essencialmente a uma forma de consciência política que visa à luta pelo poder na sociedade de classes. A cultura só é reconhecida em sua potencialidade política de tornar o povo consciente de sua situação histórica. Isso levará Estevam a afirmar, no Manifesto CPC/UNE, de 1962, que "em nosso país em nossa época, fora da arte política não há arte popular" (MARTINS, 1981, p. 131).

Uma acepção diferente de cultura popular advém do MCP surgido no Recife, no início da década de 1960, a partir de uma aliança do então prefeito Miguel Arraes com artistas e educadores voluntários, motivados por valores de igualdade e justiça sociais. Compunham o órgão executivo Germano Coelho, Anita Paes Barreto, Paulo Freire, entre outros. Partiu-se de um diagnóstico da situação socioeconômica da população em relação ao analfabetismo, à pobreza, à exclusão social e política das classes subalternas. Historicamente, de acordo com a análise do grupo, a educação foi um instrumento que fortaleceu as estruturas e valores estabelecidos pelas classes dominantes. Nesse sentido era necessário desenvolver novos instrumentos educacionais capazes 
de transformar esta realidade. Suas políticas culturais, além da alfabetização, envolviam atividades de teatro, cinema, música e artes plásticas. Sob a influência do teatro Arena de São Paulo, surgiu o Teatro de Cultura Popular com o objetivo de levar teatro às periferias. No âmbito educacional, surgiram os Núcleos Populares, cuja função era a de contribuir para a formação política, começando pela alfabetização e formar líderes populares a partir do diálogo com as comunidades periféricas. De acordo com o Estatuto do MCP, de 1961, eles tinham como objetivos incentivar a "educação de jovens e adultos" (Art. 10); a "elevação do nível cultural do povo preparando-o para a vida e para o trabalho" (Art. 30); "colaborar na melhoria do [seu] nível material" (Art. 4); formação de "quadros destinados a interpretar, sistematizar e transmitir os múltiplos aspectos da cultura popular" (Art. 5०) (MCP, 1961).

Segundo Souza, esse foi um movimento de orientação cristã e comunista e foi esta polarização de concepções ideológicas que contribuiu para acomodar dentro do grupo diferentes perspectivas, bem como questionar o elitismo cultural letrado. Também, por isso, se tornou um movimento sem bandeira político-partidária. Havia uma necessidade, e mesmo uma diretriz como se nota no estatuto, de se compreender o sentido das manifestações culturais populares para, só a partir desse entendimento, formular suas políticas culturais. Tinham como objetivo, por um lado, valorizar a cultura popular e, por outro, trazer para o debate suas necessidades latentes e bloqueadas pela dominação das classes superiores, ou seja, não concebiam a tradição do folclore e a conscientização política de forma antagônica, como Estevam Martins do CPC. Não obstante, a cultura popular tradicional não poderia ser entendida separadamente das contradições sociais e econômicas do modo de produção capitalista (SOUZA, 2014, p. 73-89). O próprio "método Paulo Freire de ensino" nasceu dessa proposta de se respeitar os saberes populares e de se partir da realidade dos educandos. $O$ alfabetizador ia a campo para perceber as palavras mais usadas e que representavam seu modo de vida, os "temas geradores", a partir dos quais se iniciava o processo educativo (COELHO, 2002, p. 64).

Tendo apresentado essas distintas formas de se entender o conceito de cultura popular, o texto passa agora a abordar sua concepção em Augusto Boal.

\section{Cultura e teatro populares em Augusto Boal}

Chama-se genericamente de teatro popular tanto as manifestações populares em geral que utilizam formas dramáticas de expressão, como os 
maracatus, festas de santos, bumba-meu-boi, congadas, carnaval e outros; como também uma outra tradição de teatro popular, de teatro propriamente dito: que se diferencia daquele reconhecido como uma das belas artes e dos grandes autores, que se apresentava, e ainda se apresenta, nas ruas das cidades, feito geralmente sem muitos recursos e com muita improvisação. Como se percebe pelo tópico acima, também ao teatro político engajado atribuímos o adjetivo "popular". Não por acaso, Boal faz uma interpretação sociopolítica do conceito de cultura popular, típica dos movimentos de esquerda da época, que relacionavam-na às ideias de revolução e de transformações sociais por meio da arte:

A cultura é produzida pela sociedade e, portanto, uma sociedade dividida em classes produzirá uma cultura dividida. Uma sociedade submetida produzirá uma cultura de submissão.

As classes dominantes tentam instituir como Cultura, a "sua" cultura e como incultura a cultura das classes dominadas. Quando muito, concedem à cultura do povo o status de "folk-lore" (conhecimento do povo). [...]

Quando se opera uma mudança revolucionária, as classes que se libertam devem libertar-se também dos valores culturais dominantes, e que lhes foram impostos pela classe dominante. Para tanto, é necessário assumir a Cultura Popular como "a" cultura, como única cultura, e negar os valores da cultura da classe dominante. Quando muito, pode-se-lhe conceder o status de "burg-lore" (conhecimento da burguesia), ou "oligo-lore" (conhecimento da oligarquia). (BOAL, 1979, p. 95).

Além disso, sua concepção de cultura popular converge com a dos movimentos mencionados, já que ambos distinguem a cultura do povo e da burguesia. No entanto, Boal, diferentemente de Martins do CPC, vai valorizar a primeira em detrimento da outra. Sem querer entrar nos méritos e deméritos da ideia de revolução na década de 1960 e 1970, importa aqui discutir a intencionalidade de Boal diante da sua proposta de uma cultura da libertação. Ele criticou a forma como os valores estéticos das classes dominantes eram elementos integrantes de uma estrutura econômico-política que servia para assegurar seu poder e, ao mesmo tempo, manter a opressão sobre as classes subalternas. Por isso, se dedicou a investigar possibilidades de transformar a atividade teatral numa prática a serviço da descolonização do saber, e da conscientização. Seu teatro fora criado, não só para a ficção, mas para constituir-se em "ações" na política cultural, ao lado das demais formas de luta empregadas pelos oprimidos. No TO, o espectador é convidado a sair de seu lugar passivo diante do espetáculo para assumir uma posição de protagonismo intervindo na cena dramática, ensaiando o que o proletariado 
e os demais oprimidos deveriam fazer no plano do real. É nesse sentido que, em Teatro do Oprimido e outras poéticas políticas, escrito no seu exílio entre 1969 e 1973, o teatro popular vai aparecer como uma "arma de liberação" potente na conscientização política do povo. No artigo Uma experiência de teatro popular no Peru ele afirma "todos devem representar, todos devem protagonizar as necessárias transformações da sociedade" (BOAL, 2005, p. 12).

Augusto Boal iniciou sua carreira teatral no Teatro de Arena de São Paulo que, como visto acima, manteve intercâmbio com o CPC e o MCP. No contexto da ditadura militar, em 71, depois de ter sido preso e torturado, Boal vai para o exílio. O Teatro do Oprimido (TO) começa a ser gestado no seu estudo sobre o teatro popular latino-americano através de experiências realizadas no Brasil, na Argentina, no Peru, na Venezuela e, posteriormente, em outros países. É nessa trajetória que Boal vai buscar as "categorias do teatro popular", presentes na obra Técnicas Latino-americanas de Teatro Popular (1979). As técnicas foram reunidas pelo autor através das experiências com teatro de rua, festas, folclore, entre outras manifestações da cultura popular.

A primeira categoria é designada "do povo e para o povo". Refere-se àqueles espetáculos apresentados para concentrações de trabalhadores, nos sindicatos, nas ruas, nas praças, nos circos, nas associações de moradores etc. Tem uma perspectiva de transformação do povo sendo, portanto, de acordo com Boal, uma categoria "eminentemente popular". Todos os temas são abordados no teatro popular, desde as peças dos grandes autores até o folclore e as festas populares (BOAL, 1979, p. 25-33). A segunda categoria é o"teatro de perspectiva popular para outro destinatário que não o povo". É o teatro com temas populares patrocinado pelos governos e por empresários para cidadãos de classe média, como pequenos-burgueses, bancários, estudantes, professores, profissionais liberais etc., ou seja, pessoas que podem compartilhar a ideologia burguesa, mas que podem mudar suas opiniões políticas. Assim se justificaria fazer um espetáculo de "perspectiva popular" para destinatários que não são o povo na medida em que sirva para que os "não-povo" tomem ciência do conhecimento popular (BOAL, 1979, p. 33-37). Esse era o tipo de teatro feito no Arena, por exemplo. A terceira, o "teatro de perspectiva anti-povo e cujo destinatário infelizmente é o povo", é o patrocinado pelas classes dominantes. Possui uma aparência popular. São programas de TV, como telenovelas, o cinema ou o teatro importado apresentado nas maiores salas. Por meio deles, as classes dominantes disseminam sua ideologia. Tem como característica evitar temas relacionados aos problemas sociais mais importantes para as classes mais baixas, como greves e manifestações 
sociais, e abordam a sociedade desde uma perspectiva do individualista cujos problemas principais seriam passíveis de serem resolvidos também ao nível do próprio indivíduo (BOAL, 1979, p. 37-42).

Estas são, de acordo com Boal, as três categorias possíveis de teatro popular. Seguindo o autor, notamos que em todas a regra é: os artistas fazem a arte e o povo a consome. OTO surge como alternativa diante destas três categorias tradicionais de teatro popular, na medida em que propõe, mediante um método aberto a modificações, que o próprio povo se aproprie da produção de seu espetáculo. Como afirmou Boal, "Não é o produto acabado que deve ser popularizado, mas sim os meios de produção". De fato, o teatro de Augusto Boal baseia-se numa tradição específica de teatro popular, o teatro engajado de Bertolt Brecht que, por influência do marxismo e de outros teatrólogos de esquerda, assume o papel de arma de conscientização e politização por meio da arte engajada. O que Boal propõe é que o TO seja uma arma contra as relações de opressão e estas se referem não somente às relações sociais de produção capitalistas, mas também ao racismo, ao machismo, à homofobia etc.

Tendo esclarecido a concepção de cultura e teatro populares para o autor, a seguir realizamos um relato de experiência de um curso realizado no Centro de Teatro do Oprimido, a partir do qual podemos compreender as práticas e teorias do TO e suas contribuições para a reflexão sobre o fazer pedagógico e a educação popular.

\section{CURSO de INTRODUÇÃO AO TEATRO dO OPRIMIDO - RELATO DE EXPERIÊNCIA}

A partir de uma experiência de formação, que teve como objetivo entender como a prática pode contribuir para a compreensão da teoria do TO, pude refletir sobre alguns problemas abordados no presente relato: em termos gerais, em que se constitui algo que possamos chamar de uma teoria do TO? Como se dá a relação entre os participantes de uma oficina de Teatro Fórum, uma das modalidades do TO, incluindo-se aqui a figura do coringa? Qual o sentido da categoria "opressão" no contexto do TO?

O Centro de Teatro do Oprimido (CTO) foi criado em 1986 no Rio de Janeiro. Como consta em seu site ${ }^{4}$, trata-se de uma instituição de pesquisa e difusão da metodologia do TO. A partir da realização de laboratórios e seminários o grupo procede à processos de "revisão, experimentação, análise e sistematização" das técnicas, jogos e exercícios. Realizam também projetos socioculturais, espetáculos e outros produtos artísticos, atuando com sua intenção na demo- 
cratização dos meios de produção cultural. Hoje, esta instituição encontra-se presente em diferentes países da África, América Latina e Europa. No Rio, o CTO localiza-se na Avenida Mem de Sá, número 31. Foi onde aconteceu o Curso de Introdução ao Teatro do Oprimido, realizado entre 24 e 26 de fevereiro de 2016, das 17 às 22 horas. $\mathrm{O}$ curso, que envolveu cerca de trinta pessoas, incluindo dois coringas, consistiu na apresentação da teoria do TO e a experimentação do método, por meio da prática de jogos e exercícios teatrais e da criação de uma cena de Teatro Fórum. O procedimento que utilizei para coleta de dados foi o registro das percepções utilizando caderno de notas e caneta esferográfica.

Via de regra, nos três dias o curso começou com práticas de jogos e exercícios de TO. O porquê dessas atividades não era explicado, a gente aprendia fazendo. Percebi que isso era proposital, uma vez que o objetivo era justamente desenvolver outras formas de linguagem. Depois os coringas explicaram que, embora o uso da palavra seja muito importante, tanto no teatro como na vida, ele acaba gerando uma espécie de perda de sensibilidade, embotando outras formas de percepção. Os jogos e exercícios constituem justamente técnicas teatrais de autoconhecimento corporal que procuram desenvolver os nossos sentidos para além da fala, inclusive de forma sinestésica. Um exemplo de jogo e exercício praticado refere-se ao que chamam de "Imagem do Som". Nessa atividade sinestésica, os coringas pediram para que formássemos uma roda e que todos ficassem de olhos fechados. Depois selecionaram um participante de cada vez para abrir os olhos e ir ao centro do círculo. Uma vez lá, este deveria pensar e expressar um som que representasse uma atividade ou um hábito social qualquer que fosse típico de uma mulher. Emitido o som, os demais praticantes poderiam, de olhos abertos, tentar dizer com palavras e gestos qual era a atividade representada.

No dia seguinte, após as apresentações dos participantes e a prática dos jogos e exercícios, a teoria do TO foi ilustrada pela Árvore do Teatro do Oprimido, desenhada num quadro posto no centro da sala, uma imagem similar à Figura 1. Nós, participantes, sentamos no chão, formando um meio círculo ao redor da "árvore", enquanto ouvíamos atentos à explicação dos coringas. O objetivo deles era, além de apresentar brevemente as diferentes técnicas que compõem o TO e mostrar as relações entre elas, contextualizar o Teatro Fórum na teoria do TO. Seguindo a imagem da árvore carregada de simbolismos, explicaram que, como o TO tem por objetivo a transformação das relações sociais reais de opressão, as técnicas dramáticas têm origem e se nutrem do conhecimento da Ética, da Política, da História, da Economia, da Filosofia, aos quais poderíamos acrescentar outros campos de conhecimentos da realidade. A partir dessa visão 
interdisciplinar da realidade social, a Estética do Oprimido, título do último livro escrito por Boal, refere-se aos fundamentos teóricos e práticos doTO. Através de meios estéticos proporcionados pelos usos da Palavra, do Som e da Imagem, tem como objetivo promover o autoconhecimento, a autoestima e a autoconfiança de maneira sinestésica e visam a estimular a descoberta das potencialidades criativas. O projeto tem como propósito desenvolver nos praticantes a capacidade de perceber (para transformar) o mundo por meio das artes como um todo e não apenas do teatro. A palavra (escrever poemas e narrativas), o som (inventar novos sons e instrumentos) e a imagem (pintar, esculpir, fotografar) são meios utilizados. Os Jogos e Exercícios surgem em primeiro lugar no tronco da árvore porque têm como função desmecanizar o corpo e a mente, acostumados às atividades repetitivas diárias, preparando-os para atuar com criatividade e liberdade. São cinco categorias de jogos e exercícios que compõem o arsenal da Estética do Oprimido: sentir tudo que se toca (procura desenvolver o tato), escutar tudo que se ouve (a audição), ativando os vários sentidos (trabalha os vários sentidos ao mesmo tempo), ver tudo que se olha (a visão) e, por fim, memória. 0 Teatro Imagem dispensa o uso das palavras com o propósito de desenvolver outras formas de percepção e de linguagem por meio do corpo, dos objetos, das cores, enfim, de imagens. Teatro Jornal é um conjunto de técnicas que utilizam a combinação de palavras e imagens que servem para desmistificar a presunção de imparcialidade dos meios de comunicação. Arco-Íris do Desejo são técnicas teatrais que procuram trabalhar opressões "internalizadas" (naturalizadas), mostrando suas origens nas relações sociais. O Teatro Fórum, por sua vez, é uma representação baseada em fatos reais que mostra uma situação opressiva apresentada como uma questão a ser resolvida. Nele, os espectadores são convidados a atuar e, de acordo com sua criatividade, revelar suas estratégias para a superação de uma relação social conflituosa. O Teatro Invisível é uma espécie de fórum que ocorre de forma velada. Os atores criam a cena de conflito em um lugar público e os transeuntes"atuam" no conflito sem saber que se trata de uma ficção. Nas Ações Diretas são utilizados todos os elementos teatrais (vestuário, dança, música) em atos públicos como protestos, marchas, desfiles, concentrações operárias, comícios e outras manifestações políticas. O Teatro legislativo é um tipo de fórum que, apresentado nas Câmaras e Assembléias legislativas, tem como objetivo a formulação de Projetos de Lei. A multiplicação refere-se aos frutos que caem no solo que devem semear e reproduzir novas Árvores do TO, ou seja, novos CTOs. Tudo isso, obviamente, demanda solidariedade entre os praticantes para reconhecer não só as próprias opressões, mas também as alheias, ou seja, demanda alteridade. 
Figura 1: Árvore do teatro do oprimido.

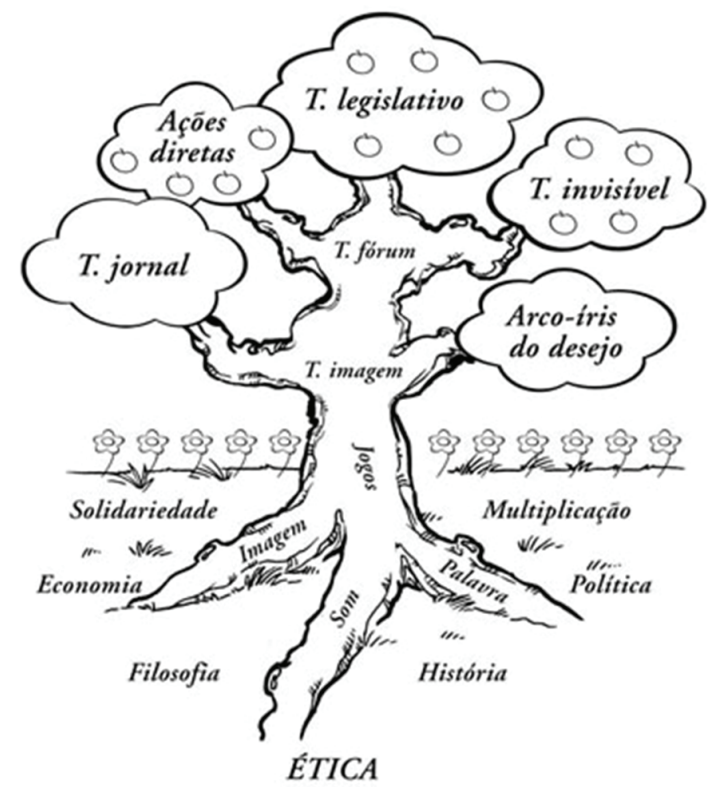

Fonte: (BOAL, 2005, p. 17).

As práticas do dia 25 permitiram problematizar o conceito de "opressão". De acordo com Boal, o TO tem dois princípios básicos: a transformação do espectador em protagonista da ação dramática, de um ser "ser passivo, recipiente, depositário", em um "sujeito criador, transformador"; e, segundo, não tratar apenas de "refletir sobre o passado" e interpretar a realidade, mas "preparar o futuro" (BOAL, 1999, p. 319). O que se pretende, com esses objetivos, é transformar relações sociais de opressão. Mas o que é "opressão"? Essa foi a questão levantada por um dos participantes durante os jogos e exercícios daquele dia. Antes de responder, em palavras, os coringas propuseram um jogo chamado "Os quatro em marcha". É um jogo tanto simples quanto esclarecedor: um grupo de quatro atores e atrizes marchavam compassados entoando um som ritmado pela marcha, como soldados, e uma quinta personagem entrava em cena e tentava se comportar da maneira como desejava, podia dançar, cantar, pular etc. Mas "os quatro em marcha" a impediam com gestos, falas e até fisicamente, não permitindo que ela agisse como queria, ou seja, de maneira diferente deles. Afinal quatro são mais fortes do que um. Nós, os demais participantes do curso, enquanto "espect-atores" tivemos que 
encontrar soluções para o problema. Quando alguém tinha uma ideia de como a personagem poderia se libertar daquela situação dizia "para!", congelando a cena, e a substituía para atuar em seu lugar. Nós, "espect-atores", tivemos ideias interessantes sobre como resolver a questão. Uma das mais interessantes, a meu ver, foi uma que convidou todos os outros espect-atores para dançar e cantar com ela, tornando-se um número bem maior que "os quatro em marcha". Ao final do jogo ficara claro quem eram os opressores e quem eram os oprimidos na cena. No entanto, a seguir, um dos coringas nos preveniu que as relações de opressão nem sempre são tão explícitas e, às vezes, pode acontecer que a mesma pessoa que oprime num contexto pode ser oprimida em outro: "o homem que oprime sua mulher em casa, muitas vezes, é o mesmo que é oprimido no seu trabalho". E, ainda, pode acontecer que uma situação que parece de explícita opressão, na verdade não seja, e outra situação que não parece, de fato o seja:"Uma relação sadomasoquista, por exemplo, é opressão? Não, não é! Porque a pessoa não só tem que sentir a opressão... ela tem que se incomodar e querer sair daquela situação. Tem que querer lutar para sair dali". É isso que caracteriza o oprimido, afirmou um dos coringas. Como disse Boal, "Oprimidos e opressores não podem ser candidamente confundidos com anjos e demônios. Quase não existem em estado puro, nem uns nem outros." (BOAL, 2005, p. 23).

Esse jogo, na verdade, constitui basicamente o que conhecemos como Teatro Fórum, embora esse possa se realizar de maneira muito mais complexa. E o que fizemos, subsequentemente, foi elaborar uma peça de Teatro Fórum. Após essa atividade, os coringas pediram que cada um de nós espect-atores escrevesse num pedaço de papel, sem colocar nossos nomes, um fato que mais Ihe marcou no ano de 2015. Posteriormente, os papéis foram colados em uma parede, dispostos de modo que todos nós pudéssemos ler cada um deles. Quando acabamos, os coringas pediram que nos dividíssemos em três grupos, cada um deveria escolher apenas um fato dentre todos que estavam colados na parede e elaborar uma cena de Teatro Fórum sobre ele. Um dos grupos escolheu uma história (verídica) de uma das participantes, uma mulher nordestina que sofreu muitos preconceitos em uma universidade no Rio de Janeiro, onde escolheu realizar sua formação acadêmica. $O$ segundo, ao qual eu pertencia, escolheu trabalhar com uma cena de assédio dentro de um ônibus, relatada por uma das participantes. $O$ último trabalhou com o assassinato de cinco jovens negros favelados que tiveram seu carro fuzilado por policiais no subúrbio do Rio, cuja notícia poucos meses antes havia chocado o país. As peças foram montadas no quarto dia. 
O último dia consistiu na elaboração dos cenários e da apresentação de uma cena de Teatro Fórum sobre cada tema escolhido. Enquanto um grupo encenava, o restante das pessoas fazia papel de espect-atores, intervindo na cena para sugerir alternativas (da nordestina, da mulher no ônibus e dos cinco meninos negros) de se libertarem da situação opressiva. Chamou a atenção nesse dia o papel desempenhado pelos coringas na encenação do Fórum. Esses podem ser vistos como artistas com função pedagógica, como especialistas e pesquisadores do TO e como facilitadores do método nas sessões de Teatro-Fórum. Cabe a eles coordenar o diálogo entre atores e espect-atores, entre palco e plateia, estimulando sua participação e orientando a análise das intervenções feitas pelos espectadores. Uma observação que julgamos interessante é que os coringas não costumavam dar respostas prontas. Eles perguntavam e induziam os participantes a criarem por si mesmos as ações possíveis. Seus discursos se deram também no sentido de explicitar que oTO não tem por objetivo ser um método milagroso que resolve todos os conflitos sociais magicamente. $O$ que ele permite é tornar conscientes determinadas relações sociais de opressão e criar intervenções possíveis no seu âmbito real: como o racismo e a homofobia. Ou seja, existem relações de opressão que não são passíveis de serem tratadas através das técnicas do TO, como, por exemplo, o caso em que um homem atira contra uma mulher desarmada, o que se pode fazer senão se desesperar e correr?

Veremos a seguir, como essa experiência tem contribuído em minha pesquisa para repensar a educação no contexto atual e ampliar as possibilidades do fazer pedagógico.

\section{REFLEXÃo SOBRE AS DIMENSÕES SOCIOEDUCATIVAS DO TEATRO DO OPRIMIDO}

A expressão Teatro do Oprimido é uma alusão à obra Pedagogia do Oprimido (PO), de Paulo Freire, livro escrito em 1968, quando o autor encontrava-se exilado no Chile, e publicado no Brasil em 1974. De fato, alguns pesquisadores têm estudado as similaridades de ideias entre as teorias desses autores. Seguindo os estudos de Teixeira, podemos listar uma série de convergências entre a PO e o TO no sentido de uma pedagogia crítica: a) que está ligada aos movimentos sociais que lutam pela justiça social por meio da superação das relações de opressão; b) que, partindo da crítica da neutralidade científica positivista, defende um posicionamento ideológico tanto na pesquisa quanto na vida social, a favor dos oprimidos; c) que pre- 
tende relações menos verticais no processo de ensino-aprendizagem por meio de uma metodologia dialógica; d) que estimula a participação ativa do educando/espect-ator no processo de construção do conhecimento; e) que constrói o conhecimento a partir da realidade concreta dos interessados e para seu benefício f) que atua na intenção de transformação da realidade pelo combate às relações sociais de opressão; que propõe intervenções socioeducativas que têm como objetivo a reflexão sobre as relações sociais humanas e a conscientização sociopolítica (TEIXEIRA, 2007, p. 121-122).

A essas convergências, podemos acrescentar mais uma, que está estreitamente relacionada ao aspecto dialógico de ambos os métodos e diz respeito ao pluralismo de ideias. Não obstante o posicionamento ideológico explícito, estes autores não defendem nada parecido com uma "doutrinação". Recusam a manipulação do conhecimento com objetivos de doutrinação político-ideológica, em detrimento do conhecimento que parta de fatos concretos e considera a pluralidade de ideias no processo dialógico de suas pedagogias. Como disse Freire,

É próprio do pensar certo a disponibilidade ao risco, a aceitação do novo que não pode ser negado ou acolhido só porque é novo, assim como o critério de recusa ao velho não é apenas o cronológico. O velho que preserva sua validade ou que encarna uma tradição ou marca uma presença no tempo continua novo.

Faz parte igualmente do pensar certo a rejeição mais decidida qualquer forma de discriminação. A prática preconceituosa de raça, de classe, de gênero ofende a substantividade do ser humano e nega radicalmente a democracia. (FREIRE, 2015, p. 17).

\section{E como disse Boal:}

[Todos nós] temos de estar do lado dos oprimidos e não de todos os lados, assim no teatro como na vida cidadã. A partir de uma clara tomada de posição, e só então, seremos neutros em relação a todos os oprimidos participantes de uma sessão de TO: devemos a todos ouvir e tentar compreender o significado de suas intervenções. A partir daí, poderemos tentar ver a coisa por todos os lados. (BOAL, 2005, p. 26).

Para Boal, trabalhar com os oprimidos é uma clara opção filosófica, política e social que tem a marca da abertura para o outro, da alteridade, e também da autonomia e da liberdade de pensamento. $O$ autor afirmara numa entrevista que "O Teatro do Oprimido incorpora da metodologia de 
Freire a proposta que cada pessoa construa seu próprio conhecimento, com liberdade, com autonomia, com um método aberto para que cada pessoa possa construir seu caminho." (apud TEIXEIRA, 2007, p. 119).

Junto a estas convergências, as observações relatadas na experiência no CTO também têm contribuído para suscitar reflexões acerca das dimensões socioeducativas do TO. Neste momento inicial da pesquisa, tanto a teoria do TO, quanto o conceito de opressão e a função do coringa têm chamado a atenção pelas possibilidades em relação à articulação com a educação popular no contexto atual e o fazer pedagógico em geral. Algumas reflexões preliminares têm orientado as atuais investigações:

a. Dada a proposta do método do TO para trabalhar temas relatados pelos espect-atores, é possível usar as técnicas do TO de maneira que possibilitem a construção do conhecimento a partir do contexto dos estudantes da educação popular? Como técnicas que tornam possível o advento dos temas geradores? Os temas geradores poderiam ser um ponto de partida para novos estudos e para construção de novos conhecimentos de maneira interdisciplinar e transversal?

b. Como a figura do coringa pode contribuir para pensarmos a formação de professores e as relações de ensino-aprendizagem atualmente? Qual é o papel do professor na educação popular hoje?

c. De que maneiras a teoria do TO, incluindo as técnicas, se relaciona com a pesquisa em educação popular, em termos metodológicos e epistemológicos?

Finalizando, chama-se à atenção para uma constatação oriunda do Curso de Introdução ao Teatro do Oprimido: para além dessas reflexões teóricas da pesquisa sobre as dimensões socioeducativas do TO, referentes ao contexto da educação institucionalizada, há aqui o reconhecimento de que o TO, enquanto fenômeno vivencial da cultura popular brasileira, só pode ser plenamente compreendido na prática concreta de seus rituais. Práticas com potencial socioeducativo, cuja experiência concreta convida a refletir sobre acontecimentos vivenciados gerando novas possibilidades advindas desse processo, como o conhecimento de novos métodos educacionais que ocorrem fora das escolas, em práticas culturais populares e que consideram a pluralidade de maneiras de pensar a sociedade. 
SOCIAL AND EDUCATIONAL DIMENSIONS OF THE THEATRE OF THE OPPRESSED: CULTURE, THEATER AND POPULAR EDUCATION

ABSTRACT: The article is divided in two parts: a discussion based on theoretical approach and an report of an experience. In the first moment based on a brief historical narrative about the concept of popular culture while an intellectual category present in a few social movements of Brazilian left wing during the decades of 50 and 60, emphasizes the conception of this concept in Augusto Boal and characterizes the Theater of Oppressed inside the tradition of a popular theater, the political theater, engaged. At last it relates with an experience in a curse of preparation in the center of Theater of Oppressed that resulted in reflections about popular education and pedagogical practice in general.

KEYWORDS: Popular culture. Theatre of the oppressed. Oppression. Pluralism.

\section{DIMENSIONES SOCIOEDUCATIVAS DEL “TEATRO DO OPRIMIDO”: CULTURA, TEATRO Y EDUCACIÓN POPULARES}

RESUMEN: Este artículo se divide en dos partes: una discusión fundamentada en estudios teóricos y un relato de experiencia. Inicialmente, partiendo de un breve relato histórico sobre el concepto de cultura popular como una categoría intelectual, presente en algunos movimientos sociales de izquierda brasileños durante las décadas de $50 \mathrm{y}$ 60 , se destaca la concepción de este concepto en Augusto Boal y caracteriza el Teatro del Oprimido dentro de determinda tradición de cultura popular, el teatro político, actuante. Por fim, relata una experiencia en un curso de formación en el "Centro de Teatro do Oprimido" que ha sucitado reflexiones sobre la educación popular y la práctica pedagógica en general.

Palabras-clave: Cultura popular. Teatro do oprimido. Opresión. Pluralismo.

\section{NOTAS}

1) O artigo faz parte de uma pesquisa de mestrado em andamento no Programa de Pós-graduação em Educação da Universidade Federal do Rio de Janeiro (UFRJ) na qual buscamos compreender a utilização da linguagem teatral na comunicação do processo de ensino-aprendizagem, articulando o Teatro do Oprimido, ensino de história e educação em direitos humanos.

2) Disponível em: <http://www.escolasempartido.org>. Acesso em: 15 jun. 2016.

3) Devido ao espaço restrito que temos aqui, só poderemos representar o conceito em seus aspectos mais gerais. Ao fazermos isso deixamos de lado toda uma dis- 
cussão acadêmica existente nas ciências humanas sobre assuntos correlatos como povo, popular, cultura, folclore, romantismo, cultura de massa, indústria cultural, multiculturalismo, hibridismo cultural etc. Além do próprio conceito de cultura popular, cuja bibliografia começa desde os autores românticos alemães, como Herder que parece ter sido o primeiro a utilizar a expressão. Assumimos também o risco de caracterizar esses movimentos sociais baseados em fontes importantes, mas que talvez não exprimam a pluralidade de opiniões de cada um. Ficaremos satisfeitos se for possível demonstrar que pelo menos alguns intelectuais protagonistas desses movimentos tinham certa concepção sobre o conceito de cultura popular.

4) Disponível em: <http://www.ctorio.org.br>. Acesso em: 15 jun. 2016.

\section{REFERÊNCIAS}

BERLINK, M. T. O CPC da UNE. São Paulo: Editora Papirus, 1984.

BOAL, A. Técnicas Latinoamericanas de Teatro Popular: uma revolução copernicana ao contrário. São Paulo: Editora Hucitec, 1979.

. Jogos para atores e não-atores. Rio de Janeiro: Civilização Brasileira, 1999.

Teatro do Oprimido e outras poéticas políticas. Rio de Janeiro: Civilização Brasileira, 2005.

BOLSONARO, C. Projeto de Lei no 867/2014. Disponível em: <http://mail.camara. rj.gov.br/APL/Legislativos/scpro1316.nsf/f6d54a9bf09ac233032579de006bfef6/55 73ae961660b4cd83257ceb006bc7d4?OpenDocument>. Acesso em: 30 mar. 2016.

CATENACCI, V. Cultura Popular: entre a tradição e a transformação. Revista Eletrônica São Paulo em Perspectiva. São Paulo: v. 15, n. 2, p. 28-35, 2001.

COELHO, G. Paulo Freire e o Movimento de Cultura Popular. In: ROSAS, P. Paulo Freire - Educação e Transformação. Recife: Editora da UFPE, 2002. p. 31-95.

FREIRE, P. Pedagogia da Atonomia. Saberes necessários à prática educativa. 5. ed. Rio de Janeiro: Editora Paz e Terra, 1996.

GUIMARÃES, L. A. P. Memória, Educação e Folclore: o pensamento de professores e folcloristas no movimento folclórico brasileiro da década de 1950. Revista Episteme Transversalis, Volta Redonda, v. 2, n. 1, p. 1-13, 2012.

GARCIA, M. A questão da cultura popular: as políticas culturais do Centro Popular de Cultura (CPC) da União Nacional dos Estudantes (UNE). Revista Brasileira de História, São Paulo, v. 24, n. 47, p. 127-162, 2004.

MANOEL, I. A.; VALE, A. M. Roland Corbisier, intelectual da cultura no ISEB e no MEC hemiplégico, nas décadas de 1950-60. Congresso Brasileiro de História da Educação, 4. 2006. Actas...: Sociedade Brasileira de História da Educação (SBHE), Eixo Temático VI, p. 1-10, 2006. 
MARTINS, C. E. MANIFESTO CPC/UNE - 1962. In: HOLLANDA, Heloisa B. Impressões de Viagem: CPC, Vanguarda e Desbunde. São Paulo, Brasiliense, 1981, p. 121-144.

MOVIMENTO DE CULTURA POPULAR. Estatuto do Movimento de Cultura Popular. Pernambuco, Recife: Movimento de Cultura Popular, 1961. Disponível em: <http://forumeja.org.br/df/files/estatuto_mcp.pdf>. Acesso em: 30 mar. 2016.

ORTIZ, R. Notas historicas sobre el concepto de cultura popular. Revista Diálogos de La Comunición, Lima, Perú, n²3, p. 1-15, 1989.

SOUZA, F. S. O Movimento de Cultura Popular do Recife (1959-1964). 128 f. 2014. Dissertação (Mestrado em História) - Faculdade de Filosofia, Letras e Ciências Humanas da Universidade de São Paulo, São Paulo, SP, 2014.

STERN, S. Pedagogia do Opressor. Escola sem Partido, 2009. Disponível em: <http:// www.escolasempartido.org /doutrina-da-doutrinacao-categoria/502-pedagogia-do-opressor>. Acesso em: 30 mar. 2016.

TEIXEIRA, T. M. B. Dimensões sócio-educativas do Teatro do Oprimido: Paulo Freire e Augusto Boal. 335 f. 2007. Tese (Doutorado em Educação) - Departamento de Pedagogia da Universidade Autônoma de Barcelona, Espanha, Barcelona, 2007.

Thiago de Oliveira AlochiO: Graduado em História pela Universi-
dade Federal do Espírito Santo (UFES). Atualmente é mestrando no
Programa de Pós-graduação em Educação da Universidade Federal do
Rio de Janeiro (UFRJ) e produtor cultural na Secretaria Adjunta de
Cultura, Ciência e Tecnologia da cidade de Maricá. Tem experiência nas
áreas de Ensino de História, Acesso aos Direitos Humanos e Produção
Cultural.
E-mail: thiagofnd30@gmail.com

